\title{
Abrigos diurnos, composição de colônias, dimorfismo sexual e reprodução do morcego hematófago Desmodus rotundus (E. Geoffroy) (Chiroptera, Phyllostomidae) no Estado de São Paulo, Brasil
}

\author{
Murilo Novaes Gomes ${ }^{1} \&$ Wilson Uieda ${ }^{2}$ \\ ${ }^{1}$ Coordenadoria de Defesa Agropecuária. Avenida Cândido X.A. Sousa 35, Regional Mogi das Cruzes, 08780-210 Mogi das \\ Cruzes, São Paulo, Brasil. E-mail: murilong@usp.br \\ ${ }^{2}$ Departamento de Zoologia, Instituto de Biociências, Universidade Estadual Paulista. 18618-000 Botucatu, São Paulo. \\ E-mail: wuieda@ibb.unesp.brou wuieda@hotmail.com
}

\begin{abstract}
Diurnal roosts, colony composition, sexual size dimorphism and reproduction of the common vampire bat Desmodus rotundus (E. Geoffroy) (Chiroptera, Phyllostomidae) from State of São Paulo, Southeastern Brazil. Although information about colonies composition of the common vampire bat Desmodus rotundus ( $\mathrm{E}$. Geoffroy, 1810) are important to the Program of the population control of vampire bat, few studies on this were carried out in Brazil. Biological data of the D. rotundus colonies from São Paulo State were obtained in 1999 and 2000 and they are presented here. In general, the natural and the man-made roosts were not big in size and they varied in their structural aspects which have influenced the bat distribution within the roosts. The vampire bat colonies had 130 individuals in average, living in three roosting sites, and several lonely bats and small groups were also found disperse within the roost. The sex rate of colonies was 1 male: 1,37 female and the most of bats caught inside the roosts was adult (89\%). Sexual size dimorphism was observed in forearm length and body mass, being females bigger than males. Most of adult males (87\%) were sexual active, but $65,5 \%$ of adult females were not pregnant.
\end{abstract}

KEY WORDS. Behavior, bionomics, southeastern Brazil, vampire bats.

RESUMO. Embora informações acerca da composição das colônias do morcego hematófago Desmodus rotundus (E. Geoffroy, 1810) sejam importantes para o controle de suas populações, poucos estudos a esse respeito foram desenvolvidos no Brasil. São apresentadas aqui informações obtidas de colônias de $D$. rotundus encontradas em 12 abrigos diurnos no Estado de São Paulo, Brasil, em 1999 e 2000. Em geral, os abrigos naturais e artificiais não possuíam grandes dimensões e estruturalmente variaram entre si. $O$ formato dos abrigos interferiu na distribuição dos indivíduos das colônias no interior dos abrigos. Essas colônias continham, em média, 130 indivíduos distribuídos em três locais no interior dos abrigos. Havia também diversos indivíduos vivendo isolados ou em pequenos grupos dispersos. A proporção entre os sexos dos morcegos capturados foi de 1 macho: 1,37 fêmeas e, em sua maioria, os morcegos capturados eram adultos (89\%). Dimorfismo sexual foi verificado estatisticamente no comprimento dos antebraços e na massa corporal, sendo as fêmeas maiores que os machos. A maior parte dos machos adultos (87\%) estava sexualmente ativo, mas 65,5\% das fêmeas adultas não estavam grávidas.

PALAVRAS CHAVE. Bionomia, comportamento, morcegos vampiros, sudeste brasileiro.

O morcego hematófago Desmodus rotundus (E. Geoffroy, 1810) tem ampla distribuição no Novo Mundo, ocorrendo desde o norte do México, América Central e até o norte da Argentina (MacNab 1973, Greenhall et al. 1983, Koopman 1988). Economicamente, esta espécie pode trazer grandes prejuízos para a pecuária da América Latina, por causa de seu papel na transmissão da raiva dos herbívoros (Greenhall et al. 1983, АсHA \& Málaga-Alba 1988). Em 1966, uma comissão da FAO (Food and
Agriculture Organization) visitou vários países da América do Sul e o México, todos afetados pela raiva em bovinos e constatou que, anualmente, aproximadamente meio milhão de cabeças morriam de raiva transmitida pelos morcegos hematófagos (Acha \& Málaga-Alba 1988). No aspecto de saúde pública, os ataques de $D$. rotundus aos seres humanos têm sido freqüentemente citados, principalmente na região Amazônica, e podem levar a transmissão de raiva (SChNeider et al. 1996, 2001). 
Os morcegos hematófagos são bastante versáteis e se adaptaram às modificações introduzidas pelo homem ao ambiente (Greenhall 1963, 1993). Diversos trabalhos (De Verteuil \& Urich 1935, Ditmars \& Greenhall 1935, Greenhall et al. 1983, TADDEI et al. 1991, BREDT et al. 1998) relataram a capacidade desta espécie em utilizar diferentes tipos de abrigos diurnos para sua sobrevivência. TADDEI et al. (1991) encontraram abrigos de D. rotundus em 337 localidades de 122 municípios do Estado de São Paulo e a maioria deles estavam localizados próximos aos principais rios paulistas. Os autores acima verificaram também que havia um maior número de abrigos artificiais na região oeste e abrigos naturais no leste do Estado, onde havia maior predominância da Floresta Atlântica e de uma topografia bastante acidentada. No Brasil, apenas BREDT et al. (1999) descreveram os abrigos utilizados por diversas espécies de morcegos, inclusive de $D$. rotundus, e a sua distribuição no interior dos mesmos. Suspeita-se que a composição das colônias de $D$. rotundus e sua distribuição no interior dos abrigos diurnos devem interferir na eficiência do controle de suas populações, através da pasta vampiricida de aplicação tópica nos morcegos. Uma colônia dividida em vários subgrupos, vivendo espalhados no interior do abrigo, deve ser mais difícil de eliminar do que uma colônia compacta vivendo em apenas um local do abrigo. Nessa situação, o formato e a estrutura dos abrigos devem influir no formato das colônias.

Habitualmente suas colônias são pequenas (GreENHALl et al. 1983) e contêm de 10 a 50 indivíduos; contudo, agrupamentos com 100 ou mais morcegos podem ocorrer principalmente em regiões onde o controle de suas populações não é feito com regularidade (UIEDA1996). Colônias maiores (cerca de 300 indivíduos) foram mencionadas por SAzIma (1978) e TADDEI et al. (1991) para o Estado de São Paulo e por BREDT et al. (1999), para a região do Distrito Federal.

Estudos têm revelado a existência de dimorfismo sexual em D. rotundus. Na região nordeste do Brasil, Alencar et al. (1994) estudaram colônias em 17 abrigos e revelaram que as fêmeas são, em média, maiores que os machos, apresentando uma massa corpórea de 37,8 g e comprimento do antebraço de $63,1 \mathrm{~mm}$, ao passo que os machos, de $35,3 \mathrm{~g}$ e $60,6 \mathrm{~mm}$, respectivamente. De maneira geral, o comprimento do antebraço pode variar de 50 a $63 \mathrm{~mm}$ e a massa corporal 15 a $50 \mathrm{~g}$, independentemente do sexo (Nowak 1991). Alencar et al. (1994) verificaram que a proporção sexual das populações em abrigos estudadas foi em média de $51,5 \%$ para fêmeas e $48,4 \%$ para machos. Resultado semelhante $(52,56 \%$ de fêmeas) foi obtido por NuñEZ \& VIANNA (1998) em um abrigo na região de Salta, na Argentina.

Na região nordeste brasileira, indivíduos machos de $D$. rotundus, com testículos escrotados e não escrotados, fêmeas em lactação (grávidas e não grávidas) foram encontrados em todos meses do ano (AlENCAR et al.1994), indicando uma reprodução contínua ao longo do ano, como já mencionado por Greenhall et al. (1983). Por outro lado, Nuñez \& Vianna (1997) verificaram que na colônia de $D$. rotundus de um abrigo da re- gião de Salta, na Argentina, havia um pico de parição na estação chuvosa.

Os dois principais objetivos do presente estudo foram: 1) Caracterizar os abrigos diurnos de D. rotundus, descrevendo seu formato e dimensão; 2) Descrever as principais características das colônias de $D$. rotundus desses abrigos, como tamanho e localização no interior dos abrigos, composição etária e sexual e condição reprodutiva dos indivíduos (atividade sexual, gestação e lactação).

\section{MATERIAL E MÉTODOS}

\section{Área de estudo}

O Estado de São Paulo possui uma área de $247.898 \mathrm{~km}^{2}$ coberta com menos de 5\% de sua vegetação nativa (Mata Atlântica e cerrado). Atualmente a maior parte do território paulista foi transformada em plantações de Cana de Açúcar e Laranja, e criação de gado bovino de corte e de leite (TADDEI et al. 1991). A expansão da bovinocultura no Estado de São Paulo favoreceu o aumento das populações de D. rotundus (TADDEI et al. 1991). Além disso, muitas estradas e rodovias foram construídas para escoar essa produção agropecuária, o que certamente contribuiu para o aumento populacional e a ampliação de sua distribuição em território paulista (TADDEI et al. 1991). Bueiros sob rodovias e pontes passaram a ser utilizados por D. rotundus como abrigos diurnos (TADDEI et al. 1991, presente estudo).

\section{Abrigos diurnos estudados}

Foram estudados 12 abrigos e seus respectivos agrupamentos de $D$. rotundus. O nome desses abrigos foi dado de acordo com seu tipo e o município onde estavam localizados. Para a definição de agrupamentos ou colônias, dentro dos abrigos diurnos, foi considerado que uma colônia é um conjunto de morcegos da mesma espécie que vive em um mesmo abrigo diurno e que contêm indivíduos de ambos os sexos, em diferentes estágios de desenvolvimento e reprodutivo. O termo agrupamento é usado como qualquer grupo de morcegos da mesma espécie, independentemente de sua composição. Para a análise da composição das colônias e agrupamentos de morcegos hematófagos, foram considerados apenas os morcegos capturados enquanto estavam saindo do abrigo no dia da captura. As características utilizadas para descrever os abrigos foram: tipo (natural ou artificial), número de aberturas, formato, dimensões (comprimento e altura, em metros), presença de outras espécies (co-habitação) e sítio de localização do agrupamento no interior do abrigo diurno.

\section{Caracterização das colônias e dos indivíduos}

Para a caracterização das colônias de D. rotundus, foram considerados o tamanho das mesmas, sua composição sexual e o estágio de desenvolvimento ontogenético e reprodutivo de seus componentes. Como não foi possível coletar todos os indivíduos das colônias estudadas, foi considerado aqui que a amostra obtida de cada colônia era um bom retrato de sua composição. 
De cada indivíduo capturado, foram verificadas as seguintes características: sexo, estágio de desenvolvimento (jovem ou adulto) determinado pelo grau de ossificação das epífises dos metacarpos e primeiras falanges das asas (ANTHONY 1988), comprimento dos antebraços (esquerdo e direito, em $\mathrm{mm}$ ) medido com auxílio de um paquímetro marca Mytutoio, massa corporal (g) de cada indivíduo medida por um dinamômetro marca Pesola e estado reprodutivo (ativos ou inativos, para machos, e grávidas ou não e lactantes ou não, para fêmeas). Foram considerados como machos ativos sexualmente, aqueles indivíduos com os testículos na bolsa escrotal e, como inativos, aqueles com os testículos na cavidade abdominal. A gravidez das fêmeas foi determinada pela palpação do seu abdome para detectar a presença do feto (RACEY 1988). Fêmeas lactantes foram reconhecidas pela presença de leite em suas mamas, que foi drenado quando os mamilos foram comprimidos com auxílio de uma pinça. Para a análise das medidas da massa corpórea, foram considerados apenas os dados dos indivíduos machos adultos e das fêmeas adultas não grávidas e das lactantes. Assim, nesta análise foram considerados 230 machos e 259 fêmeas. A análise da medida dos antebraços foi realizada em 230 machos e 331 fêmeas, todos indivíduos adultos.

\section{Sessões noturnas de capturas}

As sessões noturnas de capturas dos morcegos foram realizadas somente na época das luas minguante e nova. Nas sessões de captura, as redes-de-espera de seis metros de comprimento foram armadas somente na(s) saída(s) dos abrigos por volta das 17:00 h e desarmadas às 23:00 h (horário de verão foi desconsiderado). Capturas dentro dos abrigos não foram feitas porque podem provocar estresse aos indivíduos residentes, quebrando sua organização social, podendo levar a fuga da maioria dos seus membros para outros abrigos. Após serem retirados da rede, os morcegos foram colocados individualmente em sacos de pano numerado. Ao final de cada sessão de captura, as redes foram recolhidas e os dados biológicos e as medidas dos morcegos foram tomadas de acordo com a descrição acima realizada.

\section{Análise dos dados}

Todas as informações foram anotadas em fichas e os abrigos diurnos caracterizados em relação às suas dimensões e localização dos indivíduos de D. rotundus. Para a análise dos dados, foi utilizado o EPIINFO 6.0 para o tratamento do banco de dados e os resultados foram descritos por meio de médias, medianas, modas, desvios padrão e proporções (DEAN et al. 1994). Os valores médios das variáveis quantitativas foram comparados pelo teste de Mann-Whitney. O valor de $\mathrm{p}$ aceito foi menor que 0,05 .

\section{RESULTADOS}

Foram estudadas colônias de D. rotundus de 12 abrigos diurnos que se localizavam nos seguintes municípios do Estado de São Paulo: Amparo (1), Icém (1), Lavrinhas (2), Morungaba (1), Neves Paulista (1), Novo Horizonte (1), Pardinho (1),
Pedreira (1), Quadra (2) e Tanabi (1). Em todos os abrigos foram capturados 626 indivíduos de D. rotundus saindo e 101 entrando nos mesmos. Os dados sobre a composição sexual, número de indivíduos capturados, data da captura, estágios de desenvolvimento e reprodutivo dos indivíduos capturados saindo dos abrigos encontram-se na tabela I.

\section{Características dos abrigos e localização das colônias Gruta Pardinho}

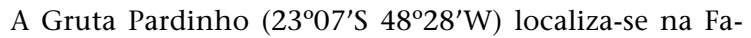
zenda Belo Jardim, km 193 da Rodovia Castello Branco acesso ao município de Pardinho. Essa gruta é constituída basicamente por um salão e uma pequena galeria. O salão tem um formato igual à metade de um cone horizontal e irregular, possuindo ca. 1,70 $\mathrm{m}$ de altura e $8 \mathrm{~m}$ de comprimento. Na parte posterior do salão, localiza-se uma galeria de aproximadamente $2 \mathrm{~m}$ de comprimento e $1,5 \mathrm{~m}$ de diâmetro. Há um pequeno curso de água nesta galeria que se estende até um dos lados da gruta. Apenas uma abertura de $5 \mathrm{~m}$ de largura no salão era utilizada pelos morcegos para sair do abrigo. O local onde se encontravam os morcegos era bastante escuro. Havia uma colônia de $D$. rotundus de cerca de (ca.) 150 indivíduos. O grupo maior da colônia (ca. 110 indivíduos) estava abrigado em um sítio no teto do canto direito da gruta. Nesse local, os morcegos penduravam-se no teto, com auxílio dos pés, e mantinham forte contato corporal, permanecendo lado a lado e/ou em contato do ventre de um sobre o dorso do outro. Nessa situação, os morcegos formavam um grupo compacto, onde a maioria mantinha algum tipo de contato corporal. O restante (40 indivíduos) estava espalhado em pequenos grupos pela galeria da gruta (grupos de dois a quatro indivíduos), praticamente sem contato corporal. Não havia outras espécies coabitando nesse abrigo.

\section{Bueiro Quadra 1}

O Bueiro Quadra $1\left(23^{\circ} 15^{\prime} \mathrm{S} 47^{\circ} 59^{\prime} \mathrm{W}\right)$ situa-se no km 151 da Rodovia Castello Branco, município de Quadra. Foi construído com manilhas de cimento e possui formato cilíndrico de ca. $50 \mathrm{~m}$ e 1,5 m de diâmetro. Possui duas saídas de água; porém, apenas uma delas estava sendo utilizada pelos morcegos, uma vez que a outra saída estava obstruída pela vegetação e acúmulo de água. O Bueiro Quadra 1 abrigava uma colônia de $D$. rotundus de ca. 200 indivíduos, que se encontravam separados em três frestas de manilhas distantes 15 m, 30 m e $40 \mathrm{~m}$ da entrada. Cada fresta abrigava, respectivamente, 70, 40 e 50 indivíduos, que formavam grupos compactos. Alguns morcegos, ca. 40 indivíduos, estavam isolados ou em pequenos grupos de dois a quatro indivíduos espalhados ao longo do bueiro, sem contato corporal. Não foram encontradas outras espécies de morcegos residindo nesse bueiro.

\section{Bueiro Quadra 2}

O Bueiro de Quadra $2\left(23^{\circ} 15^{\prime} \mathrm{S} 48^{\circ} 01^{\prime} \mathrm{W}\right)$ também localiza-se no km 146,5 da Rodovia Castello Branco, município de Quadra. Possui dimensões semelhantes ao bueiro anterior; 
Tabela I. Agrupamentos de Desmodus rotundus estudados em 12 abrigos diurnos no Estado de São Paulo, entre 1999 e 2000 . Os dados mostrados estão separados por abrigo, por período de captura, por estágios de desenvolvimento e de reprodução, e por sexos. Nenhuma fêmea em lactação estava também aparentemente grávida. (NGR) Não grávida, (GRA) Grávida, (LAC) Lactante.

\begin{tabular}{|c|c|c|c|c|c|c|c|c|c|}
\hline \multirow{3}{*}{ Abrigos diurnos } & \multirow{3}{*}{ Mês de captura } & \multicolumn{5}{|c|}{ Morcegos adultos } & \multicolumn{2}{|c|}{ Jovens } & \multirow{3}{*}{ Total } \\
\hline & & \multicolumn{2}{|c|}{ Machos } & \multicolumn{3}{|c|}{ Fêmeas } & \multirow[t]{2}{*}{ Machos } & \multirow[t]{2}{*}{ Fêmeas } & \\
\hline & & Ativo & Inativo & NGR & GRA & LAC & & & \\
\hline Gruta Pardinho & $12 / 1999$ & 13 & 3 & 15 & 5 & 3 & 1 & - & 40 \\
\hline Bueiro Quadra 1 & $03 / 2000$ & 21 & 6 & 45 & 6 & 7 & 4 & 12 & 101 \\
\hline Bueiro Quadra 2 & $04 / 2000$ & 28 & 6 & 25 & 11 & 7 & 8 & 3 & 88 \\
\hline Ponte Icém & $05 / 2000$ & 23 & - & 20 & 1 & - & 3 & 1 & 48 \\
\hline Casa Tanabi & $05 / 2000$ & 16 & - & 17 & 6 & 8 & 4 & 4 & 55 \\
\hline Gruta Lavrinhas 1 & $06 / 2000$ & 13 & 4 & 15 & 2 & 3 & 1 & 4 & 42 \\
\hline Gruta Pedreira & $06 / 2000$ & 19 & 5 & 30 & 4 & 2 & 4 & 2 & 66 \\
\hline Casa N. Paulista & $07 / 2000$ & 14 & - & 10 & 3 & 2 & 1 & 1 & 31 \\
\hline Tulha N. Horizonte & $07 / 2000$ & 31 & 3 & 17 & 7 & 4 & 3 & - & 65 \\
\hline Bueiro Amparo & $08 / 2000$ & 13 & 1 & 9 & 8 & 2 & 1 & 2 & 36 \\
\hline Gruta Lavrinhas 2 & $08 / 2000$ & 5 & - & 5 & 2 & - & 2 & 2 & 16 \\
\hline Bueiro Morungaba & $08 / 2000$ & 5 & 1 & 12 & 17 & 1 & 2 & - & 38 \\
\hline Total & & 201 & 29 & 217 & 72 & 42 & 34 & 31 & 626 \\
\hline
\end{tabular}

porém, aqui os morcegos utilizavam as duas aberturas do bueiro. O abrigo Quadra 2 hospedava uma colônia de ca. 170 indivíduos de D. rotundus, que se localizava principalmente em duas frestas entre as manilhas, distantes $15 \mathrm{~m}$ e $30 \mathrm{~m}$ de uma das bocas do bueiro. Em cada fresta, havia ca. 60 indivíduos pendurados de modo compacto. Outros morcegos (50) compreendiam indivíduos solitários ou pequenos grupos de dois a quatro, sem contato corporal, que permaneciam pendurados nas laterais e no teto ao longo do bueiro. Não havia outras espécies de morcegos residindo neste abrigo.

\section{Ponte Icém}

O abrigo diurno Ponte Icém $\left(20^{\circ} 16^{\prime} \mathrm{S} 49^{\circ} 16^{\prime} \mathrm{W}\right)$ de $D$. rotundus situa-se sob uma ponte de concreto no $\mathrm{km} 34$ da rodovia Icém - Paulo de Faria, município de Icém. Esta ponte possui ca. $50 \mathrm{~m}$ de comprimento e foi construída sobre um pequeno córrego. Nas duas margens do córrego, a ponte é sustentada por dois pilares de concreto, unidos por uma parede de 1,80 m de altura e $10 \mathrm{~m}$ de largura, que (é também a largura da estrada), pelo tabuleiro da ponte que possui $10 \mathrm{~m}$ de largura e quatro de comprimento (na parte onde se encontravam os morcegos) e dois taludes com $50^{\circ}$ de inclinação do chão. Os morcegos usavam como abrigo o espaço vazio formado pelos pilares, a parede, o tabuleiro da ponte e o talude dos dois lados da ponte (nas duas margens do córrego). No presente estudo, os dois lados da ponte foram considerados como um único abrigo diurno. Os morcegos utilizavam como saídas as laterais dos trapézios formados pelos pilares com o talude e tabuleiro. Esse abrigo diurno era ocupado por uma colônia compacta de ca. 120 indivíduos de D. rotundus e outra de ca. 30 indivíduos de Carollia sp.

No espaço vazio de um dos lados da ponte, foram localizados 25 indivíduos que estavam distribuídos isoladamente e sem contato corporal. Do outro lado da ponte, havia ca. 80 morcegos abrigados de modo compactado e mantendo um extenso contato corporal, em um nicho localizado no vértice superior de $90^{\circ}$ do pilar da ponte. Havia ainda alguns indivíduos isolados por todo abrigo e um grupo de ca. 15 morcegos pendurados, lado a lado e com contato corporal apenas dos antebraços das asas, na parede vertical ao lado do agrupamento compacto.

\section{Casa Tanabi}

A colônia de $D$. rotundus abrigava-se numa casa abandonada de alvenaria e telha de barro $\left(20^{\circ} 42^{\prime} \mathrm{S} 49^{\circ} 38^{\prime} \mathrm{W}\right)$ localizada na Fazenda São José, município de Tanabi. Esta casa possui ca. $80 \mathrm{~m}^{2}$, sem forro, seis cômodos no mesmo nível e uma cozinha, em um nível inferior do terreno. Os morcegos saíam da casa pela janela aberta da cozinha. O telhado, em telhas de barro, é formado por quatro águas com uma viga principal de, aproximadamente, $10 \mathrm{~m}$ de comprimento e colocada a $5 \mathrm{~m}$ do chão. Havia um número aproximado de 130 indivíduos de $D$. rotundus, dos quais 100 abrigavam-se, de modo compacto, em um sítio no lado oeste da casa, no vértice da viga principal com as duas vigas secundárias e o telhado. Parte dos morcegos (ca. 30) repousava lado a lado e sem contato corporal, formando duas fileiras entre as vigas secundárias e o telhado. Distavam do agrupamento principal apenas $30 \mathrm{~cm}$. 


\section{Gruta Lavrinhas 1}

A gruta Lavrinhas $1\left(22^{\circ} 36^{\prime} \mathrm{S} 44^{\circ} 52^{\prime} \mathrm{W}\right)$ situa-se próximo ao km 26 da Rodovia Presidente Dutra, município de Lavrinhas. Constituída por vários matacões sobrepostos que formavam um abrigo de apenas uma saída. O espaço interior é irregular por causa das pedras salientes e da erosão provocada pela água das chuvas. A maior altura interna da gruta é de $2 \mathrm{~m}$, sendo a largura máxima de $1,5 \mathrm{~m}$ e a profundidade de $2,5 \mathrm{~m}$. Nas pedras de seu interior era possível observar fungos e briófitas, comuns neste tipo de ambiente.

Apenas D. rotundus residia na Gruta Lavrinhas 1 e sua colônia tinha ca. 100 indivíduos. Um grupo de 70 dos 100 morcegos abrigava-se, de modo compacto, em um único sítio localizado em uma fenda de ca. $1 \mathrm{~m}$ de diâmetro por $2 \mathrm{~m}$ de comprimento. Os outros indivíduos estavam espalhados isoladamente ou em pequenos grupos de dois a três indivíduos pelo abrigo, sem contato corporal.

\section{Gruta Pedreira}

A Gruta Pedreira $\left(22^{\circ} 49^{\prime} \mathrm{S} 46^{\circ} 53^{\prime} \mathrm{W}\right)$ localiza-se na fazenda São João, município de Pedreira. Formada por três grandes rochas e alguns matacões, que criam uma cavidade interna em forma de meia esfera a uma distância de $50 \mathrm{~m}$ de uma lagoa. Seu espaço interno tem uma altura média de ca. $3 \mathrm{~m}$ e uma área de ca. $50 \mathrm{~m}^{2}$ ao nível do chão. Esta gruta possui duas aberturas laterais em forma de fenda muito próximas entre si, com tamanho médio de $1 \mathrm{~m}$ de altura por 0,6 $\mathrm{m}$ de largura. No teto, há duas fendas de $2 \mathrm{~m}$ de comprimento por $0,8 \mathrm{~m}$ de largura, que não se abrem para o exterior.

A colônia de D. rotundus possuía ca. 220 morcegos e ocupava dois sítios, um em cada fenda do teto da gruta. Cada sítio abrigava ca. 90 indivíduos pendurados no teto, de modo compacto. Foram observados 30 outros indivíduos espalhados isoladamente e em pequenos grupos de dois a quatro indivíduos, que se penduravam pelas paredes do abrigo, sem contato corporal.

\section{Casa Neves Paulista}

O abrigo diurno de $D$. rotundus no município de Neves Paulista era uma casa abandonada $\left(20^{\circ} 46^{\prime} \mathrm{S} 49^{\circ} 36^{\prime} \mathrm{W}\right)$ da área rural, sem forro, que se encontrava abandonada naquele momento de nossa visita. A casa possui cinco cômodos e uma cozinha separada por uma área. O telhado, em telhas de barro, apresenta quatro águas e uma viga principal de ca. $12 \mathrm{~m}$ de comprimento e $5 \mathrm{~m}$ de altura. Nos dois lados do fundo da casa, havia um espaço livre entre o telhado e a parede que era utilizado como saída dos morcegos.

Foram observados ca. 80 indivíduos de D. rotundus, dos quais 60 se abrigavam, de modo compacto, no vértice da viga principal com as vigas secundárias e o telhado. Outros 20 morcegos repousavam, lado a lado e sem contato corporal, na viga principal que sustenta o telhado.

\section{Tulha Novo Horizonte}

A Tulha de Novo Horizonte $\left(21^{\circ} 25^{\prime} \mathrm{S} 49^{\circ} 19^{\prime} \mathrm{W}\right)$ localiza- da na Fazenda Santa Maria, município de Novo Horizonte, e foi construída em madeira. Na ocasião da coleta de dados, a tulha encontrava-se abandonada. Possuía ca. $250 \mathrm{~m}^{2}$ e distava $10 \mathrm{~m}$ de um córrego. Era constituída por um grande salão, um corredor de ca. 1,5 $\mathrm{m}$ de largura, por $10 \mathrm{~m}$ de comprimento e 4 $\mathrm{m}$ de altura, e um cômodo de ca. $20 \mathrm{~m}^{2}$ e 1,8 m de altura, onde havia um motor propulsor de esteira abandonado para transportar sacas de café.

Havia ca. 110 indivíduos de D. rotundus abrigados principalmente em dois sítios. Em um deles, ca. 40 morcegos estavam se abrigando entre a parede do corredor e o telhado e no outro, 50 indivíduos se abrigavam embaixo do motor a uma altura de aproximadamente um metro do chão. Em ambos os grupos, os morcegos mantinham intenso contato corporal entre si. Outros 20 indivíduos foram observados enquanto pendurados isoladamente nas paredes do corredor ou em pequenos grupos pendurados, sem contato corporal, no teto do cômodo de $20 \mathrm{~m}^{2}$. Neste cômodo, vivia também um agrupamento de 20 indivíduos de Glossophaga soricina (Pallas, 1766), que se penduravam no teto com auxílio apenas dos pés e não mantinham contato corporal. Indivíduos de ambas espécies utilizavam a abertura do corredor e o vão da porta do cômodo como saída do abrigo.

\section{Bueiro Amparo}

O Bueiro Amparo (22 $44^{\prime} \mathrm{S} 46^{\circ} 45^{\prime} \mathrm{W}$ ) localiza-se no km 116 da estrada Morungaba-Amparo, município de Amparo. O bueiro é antigo e foi inteiramente construído com pedras de granito, na forma de paralelepípedo. Por causa do desnível do terreno, o bueiro apresentava a forma de escada com cinco degraus (cada degrau possuindo aproximadamente $0,8 \mathrm{~m}$ de largura, 1,5 m de comprimento e $1 \mathrm{~m}$ de altura). Há duas aberturas, uma de cada lado da estrada, e um comprimento total do bueiro de ca. $20 \mathrm{~m}$. Neste bueiro havia uma colônia de ca. 120 indivíduos de $D$. rotundus, dos quais 80 se abrigavam, de modo compacto, em uma fresta entre duas pedras no patamar do segundo degrau. O restante encontrava-se pendurado nas pedras, principalmente do patamar do quarto degrau, e formava uma fileira de morcegos nos dois cantos superiores, com aproximadamente 20 indivíduos cada uma e, de modo geral, sem contato corporal.

\section{Gruta Lavrinhas 2}

A gruta Lavrinhas $2\left(22^{\circ} 34^{\prime} \mathrm{S} 44^{\circ} 55^{\prime} \mathrm{W}\right)$ é formada por um conjunto de pedras fundidas (em forma de um paralelepípedo) com muitas briófitas e fungos crescendo e estava localizada ao pé de um morro do município de Lavrinhas. A gruta contém apenas um pequeno salão cilíndrico vertical com 2,5 $\mathrm{m}$ de altura e $0,8 \mathrm{~m}$ de diâmetro. A parte superior interna da gruta é um pouco mais larga e possui uma nascente de água que saía pela abertura na parte inferior das pedras fundidas. Por essa abertura saíam os morcegos hematófagos para suas atividades noturnas.

A colônia de D. rotundus foi calculada em ca. 60 indivíduos, dos quais a maioria (50) abrigava-se, de modo compacto,

Revista Brasileira de Zoologia 21 (3): 629-638, setembro 2004 
na parte superior, mais larga, da gruta. O restante dos indivíduos repousava isoladamente ou em pequenos grupos de 2 a 3 , sem contato corporal, nas paredes laterais da gruta.

\section{Bueiro Morungaba}

O Bueiro Morungaba (22 $\left.51^{\prime} \mathrm{S} 46^{\circ} 47^{\prime} \mathrm{W}\right)$ localizado no km 109 da estrada Morungaba-Amparo, município de Morungaba, e foi construído com pedras de granito na forma de paralelepípedo, possui duas saídas, uma de cada lado da estrada. Apenas uma das aberturas era utilizada pelos morcegos hematófagos, uma vez que a outra se encontrava obstruída pela vegetação, acumulando água em uma das extremidades.

Internamente, este abrigo possuía ca.1,40 m de altura, $10 \mathrm{~m}$ de comprimento, $0,8 \mathrm{~m}$ de largura. A colônia de $D$. rotundus possuía ca. 100 morcegos, que se abrigavam principalmente, em duas frestas entre as pedras de granito. As frestas distavam 4 e $6 \mathrm{~m}$ da abertura utilizada como saída pelos morcegos. Cerca de 40 indivíduos foram observados enquanto pendurados, de modo compacto, em cada fresta e 20 outros se encontravam dispersos isoladamente e em pequenos grupos de dois a quatro indivíduos, sem contato corporal.

\section{Características das colônias de Desmodus rotundus}

\section{Tamanho das colônias e número de morcegos capturados}

O tamanho médio das colônias estudadas de $D$. rotundus foi de 130 indivíduos, com a menor contendo ca. 60 (Gruta Lavrinhas 2) e a maior, 220 morcegos (Gruta Pedreira). Apesar do cuidadoso trabalho de captura noturna dos morcegos na entrada dos abrigos diurnos, não foi possível coletar a maioria dos indivíduos das colônias, de acordo com a estimativa prévia feita no período da tarde do mesmo dia da coleta. De modo geral, foram capturados uma média de $46 \%$ dos indivíduos do tamanho estimado das colônias (Fig. 1), com um mínimo de $26,7 \%$ nas Grutas Pardinho e Lavrinhas 2 e um máximo de $59,1 \%$ na Tulha Novo Horizonte.

\section{Proporção de jovens e adultos}

Os dados das coletas noturnas de D. rotundus na entrada dos abrigos diurnos estudados mostram que suas colônias eram constituídas basicamente por indivíduos adultos (Fig. 2), em uma proporção de 8,5 adultos para cada jovem capturado. Em algumas delas, como nas residentes na Gruta Pardinho e na Tulha Novo Horizonte, os jovens capturados constituíam menos de 5\% da colônia. Apenas na Gruta Lavrinhas 2 foi capturado um maior número (25\%) de jovens saindo do abrigo.

\section{Proporção dos sexos nas colônias}

De modo geral, a proporção de indivíduos fêmeas $(\mathrm{N}=$ 362 ), incluindo jovens e adultos, de $D$. rotundus capturados nos abrigos estudados, foi maior do que a de machos ( $\mathrm{N}=264)$ (Fig. 3), em uma proporção sexual média de 1:1,37 machos/fêmeas. Essa tendência foi verdadeira para $83,3 \%$ dos abrigos estudados (1:1,41 machos/fêmeas). A maior incidência de indivíduos machos ocorreu apenas em dois abrigos (16,7\%), que apresentaram uma proporção sexual média de 1,06:1 machos/fêmeas.
Quando se compararam os dados de somente indivíduos adultos, essa mesma tendência foi observada em proporções semelhantes (Fig. 4) para todos os abrigos. Por outro lado, os dados dos indivíduos jovens mostravam um resultado diferente, tendo sido capturados de modo geral, mais machos jovens do que fêmeas jovens, apesar da diferença ser pequena (Fig. 5).

\section{Reprodução}

Os dados obtidos referem-se basicamente às condições reprodutivas de $D$. rotundus na estação seca (abril a setembro), no Estado de São Paulo. Machos sexualmente ativos foram capturados em todas as colônias estudadas (Fig. 6). Em 33,3\% das colônias, todos os machos coletados estavam ativos, enquanto que nas outras, mais de $75 \%$ deles estavam sexualmente ativos.

Por outro lado, não foi percebida atividade reprodutiva (prenhez e/ou lactância) na maioria das fêmeas estudadas $(66,5 \%)$ na estação seca, no Estado de São Paulo (Fig. 7). Apenas em dois abrigos $(16,7 \%)$, foi constatado que havia mais fêmeas com atividade reprodutiva nas colônias do que não reprodutiva e ambas foram estudadas no mês de agosto. $\mathrm{O}$ estado reprodutivo dos adultos capturados de D. rotundus nos diferentes abrigos diurnos não teve grandes variações. Em cinco colônias, os machos ativos foram os mais capturados (Bueiro Quadra 2, Tulha Novo Horizonte, Ponte Icém, Bueiro Amparo e Casa Neves Paulista).

\section{Dimorfismo sexual}

Tanto os dados do comprimento dos antebraços quanto os da massa corporal dos morcegos (Tab. II) mostraram a ocorrência de dimorfismo sexual, estatisticamente significativa ( $\mathrm{p}<0,0001)$. Em ambos, as fêmeas foram maiores e mais pesadas que os machos. Os abrigos que apresentaram as fêmeas de maior porte foram Ponte Icém, Bueiro Quadra 2, Gruta Pardinho. Machos grandes foram encontrados apenas na Gruta Pardinho. As fêmeas mais pesadas foram encontradas na Gruta Pardinho e na Casa Neves Paulista, e os machos mais pesados, na Gruta Pardinho e Casa Tanabi.

\section{DISCUSSÃO}

\section{Tipos de abrigos diurnos}

No presente estudo, colônias de D. rotundus foram encontradas tanto em abrigos artificiais (como pontes, casas e bueiros) $(66,7 \%)$, como em naturais (grutas) $(33,3 \%)$. Os dados do presente estudo não diferem daqueles encontrados por TADDEI et al. (1991), também para o Estado de São Paulo. Esses autores verificaram que apenas $24,8 \%$ dos 113 abrigos diurnos de $D$. rotundus eram naturais. Os abrigos artificiais eram principalmente casas abandonadas no campo, pontes, fornos de carvão, poços d'água abandonados, bueiros sob rodovias e outras estruturas similares (TADDEI et al. 1991). Diversos trabalhos (DE Verteuil \& Urich 1935, Ditmars \& Greenhall 1935, Taddei et al. 1991, BREDT et al. 1998) já relataram a capacidade dessa espécie em utilizar diferentes tipos de abrigos diurnos. Essa capacidade, sob diferentes condições, mostra a grande versatilidade 

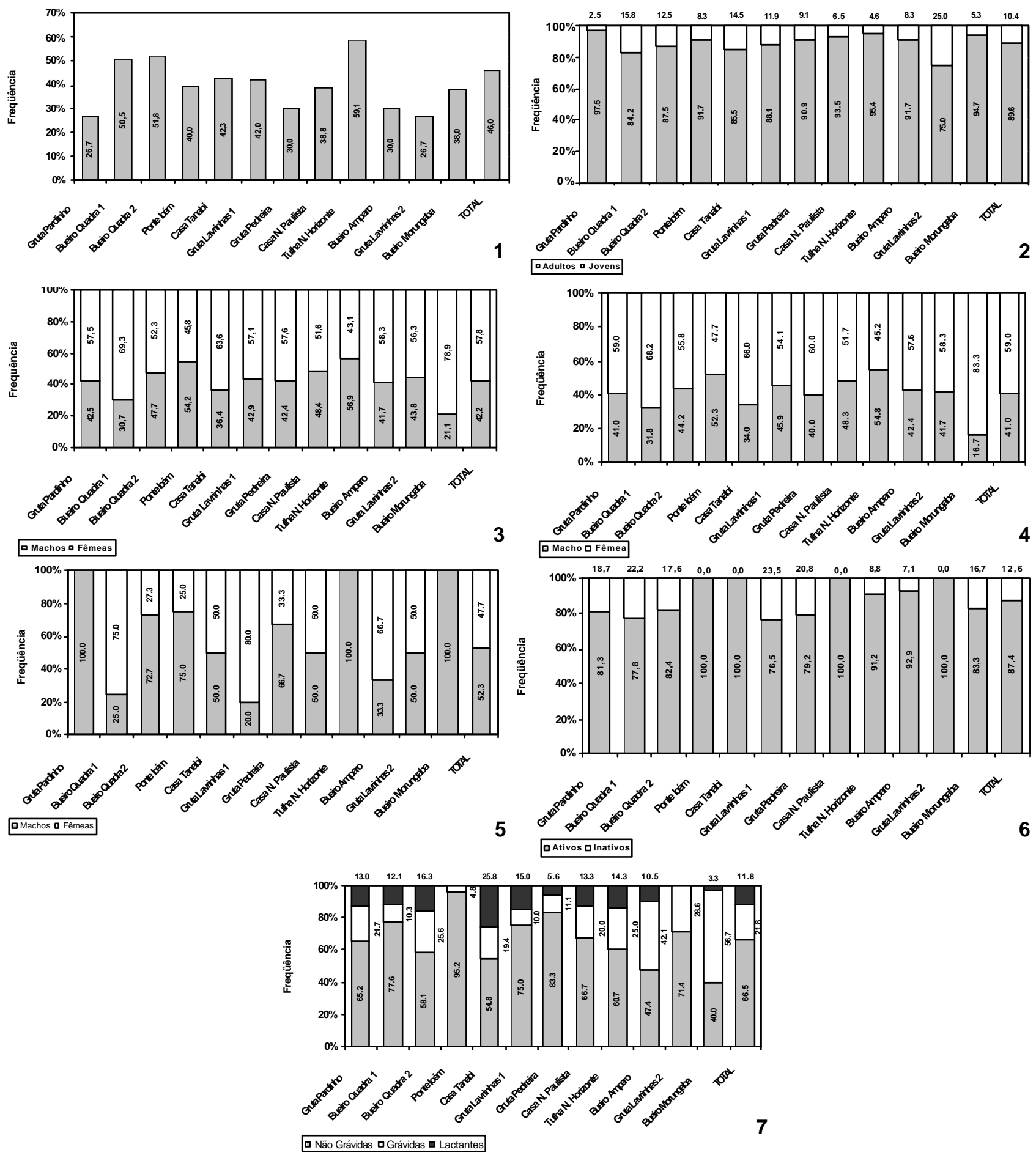

Figura 1. Desmodus rotundus, capturadosem 12 abrigos diurnos no Estado de São Paulo, em 1999 e 2000: (1) razão entre indivíduos capturadose estimados; (2) proporção de indivíduos adultose jovens; (3) proporção sexual detodos os indivíduos (jovens +adultos); (4) proporção sexual de indivíduos adultos; (5) proporção sexual de indivíduosjovens; (6) proporção de machos sexualmente ativose inativos; (7) proporção do estado reprodutivo de fêmeas. 
Tabela II. Média, desvio padrão, valor máximo e mínimo, mediana e moda da medida do antebraço direito, antebraço esquerdo e massa corpórea de indivíduos de $D$. rotundus capturados em 12 abrigos diurnos do Estado de São Paulo, entre 1999 e 2000. Os dados estão separados por sexo. *Nível descritivo do teste de Mann-Whitney.

\begin{tabular}{clrrr}
\hline Variáveis & Parâmetro & Fêmea & Macho & \multicolumn{1}{c}{$\mathrm{p}^{*}$} \\
\hline & Média & 64,1 & 61,2 & $<0,0001$ \\
& Desvio Padrão & 1,7 & 1,9 & \\
Antebraço & Mínimo & 60,1 & 56,8 & \\
Direito (mm) & Máximo & 70,0 & 69,8 & \\
& Mediana & 64,1 & 61,0 & \\
& Moda & 63,7 & 60,0 & \\
\hline & Média & 64,0 & 61,2 & $<0,0001$ \\
Antebraço & Desvio Padrão & 1,6 & 1,7 & \\
Esquerdo & Mínimo & 60,1 & 57,7 & \\
(mm) & Máximo & 70,1 & 69,9 & \\
& Mediana & 64,1 & 61,2 & \\
& Moda & 63,2 & 60,0 & \\
\hline & Média & 39,1 & 35,3 & $<0,0001$ \\
& Desvio Padrão & 2,9 & 2,7 & \\
Massa & Mínimo & 31,0 & 29,0 & \\
corpórea (g) & Máximo & 48,0 & 44,0 & \\
& Mediana & 39,0 & 35,0 & \\
& Moda & 38,0 & 35,0 &
\end{tabular}

adaptativa de D. rotundus, já salientada por SAZIMA (1978), TADDEI et al. (1991) e BREDT et al. (1998).

A distribuição espacial dos indivíduos de D. rotundus no interior dos diferentes abrigos estudados no Estado de São Paulo foi similar entre si e, de modo geral, uma colônia era constituída por um a três grandes agrupamentos principais e diversos outros indivíduos espalhados, isoladamente e/ou em pequenos grupos, pelo interior dos abrigos. Esse tipo de distribuição espacial dos indivíduos está intimamente relacionado às variações topográficas dos abrigos paulistas estudados. O formato dessas colônias é uma característica muito importante na propagação intraespecífica da raiva em $D$. rotundus e na eficácia da pasta vampiricida de uso tópico em morcegos. Nossa hipótese é que a divisão das colônias dentro dos abrigos, provocada pela estrutura dos mesmos, afeta a eficiência dessa pasta, reduzindo-a sensivelmente.

\section{Características das colônias}

De acordo com Wilkinson (1990), o grupo principal de uma colônia de D. rotundus da Costa Rica é constituído basicamente por fêmeas e seus filhotes, que são protegidos por um macho dominante (alfa). Os indivíduos isolados e os pequenos grupos espalhados pelo abrigo seriam machos solteiros (ou subalternos ou satélites, isto é, inferiores hierarquicamente ao macho alfa). Um dos obstáculos aos dados de WiLKINSON (1990) é que seu estudo foi feito com colônias pequenas (8 a 12 indivíduos) vivendo em ocos-de-árvores e em duas áreas de florestais, relativamente bem protegidas (Hacienda La Pacifica e Parque Nacional de Santa Rosa). Como seria a estrutura social de colônias maiores, vivendo em abrigos amplos em áreas de intensa atividade econômica, como ocorrem no Estado de São Paulo? O segundo autor (W. Uieda) obteve um dado no município de Curvelo, Estado de Minas Gerais, que sugere que a distribuição espacial dos indivíduos em uma caverna pode não ser diferente. Em setembro de 1994, este autor capturou somente indivíduos machos de $D$. rotundus em duas redes armadas junto aos pequenos grupos de indivíduos e, principalmente, fêmeas, em duas redes armadas junto ao grande agrupamento desta espécie no interior da caverna. Considerando que isto possa ser verdadeiro também para colônias de outras regiões, os grandes agrupamentos do presente estudo seriam constituídos de fêmeas, em diferentes estágios reprodutivos, e seus filhotes, além de um ou mais machos alfa. Os indivíduos isolados ou pequenos grupos poderiam ser os machos solteiros, à espera de uma oportunidade para copular com as fêmeas do agrupamento principal.

Wimsatt (1969) no México e Crespo et al. (1961) e Nuñez \& Vianna (1998) na Argentina, utilizando a técnica de marcação e recaptura, coletaram uma proporção semelhante de indivíduos, machos e fêmeas, de $D$. rotundus em diversos abrigos estudados. Seus dados indicaram uma razão sexual de aproximadamente 1:1 nas colônias dessa espécie. Nos abrigos estudados no Estado de São Paulo, foi encontrada a proporção sexual de 1:1,37, com a presença de um número maior de fêmeas do que de machos. NuÑEz \& VIANNA (1998) relataram que a proporção entre machos e fêmeas, descritos em diversos trabalhos, apresentava resultados que variavam de acordo com a distribuição populacional da espécie, tamanho da amostra ou do método utilizado para sua captura. É possível que o período do ano, as condições climáticas e o tempo de coleta dos morcegos ao longo da noite possam também interferir na proporção sexual dos indivíduos coletados. Os dados do presente estudo foram obtidos basicamente na estação seca e mais fria do ano, sem luar, e por um tempo prolongado de captura noturna (17:00 às 23:00 h). Além disso, foram considerados como membros de uma colônia, somente aqueles indivíduos que foram capturados enquanto estavam saindo do abrigo, sendo desconsiderados aqueles que estavam entrando. Um número menor de machos pode ser uma indicação de que parte deles, na estação seca, já se deslocara para outros abrigos e/ou regiões à procura de novos territórios para formarem novos haréns.

O tamanho médio de 130 indivíduos por colônias está acima do tamanho considerado habitual de 20 a 100 (WILKINSON 1988, Greenhall et al. 1983, GreEenhall 1993, Uieda et al. 1996). No Estado de São Paulo, TAdDEI et al. (1991) consideraram como colônias antigas e estabilizadas, aquelas com mais de 51 indivíduos. No seu estudo, $58 \%$ das colônias $(\mathrm{N}=31)$ continham 
mais de 151 indivíduos. Para Uieda et al. (1996), colônias maiores que 100 indivíduos ocorrem em regiões onde o trabalho de controle de populações não é feito com regularidade. Essa situação foi encontrada nos municípios de Pardinho, Pedreira, Quadra, Morungaba, Lavrinhas, Amparo e Novo Horizonte, onde se encontrava parte dos abrigos estudados. Durante as atividades de controle da raiva dos herbívoros realizadas pela Coordenadoria de Defesa Agropecuária na região de Bragança Paulista, o primeiro autor (M.N. Gomes) encontrou um bueiro na estrada Amparo-Itapira (na divisa entre os dois municípios) uma colônia de ca. 800 indivíduos de $D$. rotundus. Colônias imensas contendo 1.000 e até 2.000 indivíduos tem sido citadas na literatura (WiLKINSON 1988, Greenhall 1993); porém, sua ocorrência é rara, ou então, foram mal dimensionadas.

\section{Reprodução}

A presença de um grande número de machos sexualmente ativos em todas as colônias estudadas no Estado de São Paulo sugere que na estação seca, a maioria dos machos deve estar à procura de fêmeas receptivas. Como a maior parte das fêmeas examinadas ainda não aparentava gravidez $(75,1 \%, \mathrm{~N}=289)$, é possível que o nascimento dos filhotes ocorra, com mais freqüência, na estação chuvosa (outubro a março), uma vez que o tempo de gestação é prolongado (sete meses) (Schmidt 1988). Na estação seca devem ocorrer muitas interações sociais, com machos alfa defendendo territórios e seus haréns contra os machos subalternos e/ou intrusos (de outras colônias). Essas interações são geralmente intimidatórias, mas podem ser também agressivas o que resultaria em ferimentos, muito comuns nos indivíduos de D. rotundus. É possível que nessas condições a circulação do vírus rábico deve ser grandemente favorecida por essas interações agonísticas (TURNER 1975), facilitando sua propagação interna nas colônias desse morcego hematófago. Outros estudos (CRespo et al. 1961, BREDT et al. 1998, AlENCAR et al. 1994), realizados respectivamente em Córdoba na Argentina, Centro-Oeste e Nordeste do Brasil, relataram que $D$. rotundus, não possuía uma estação reprodutiva definida pois encontrava alimentos disponíveis o ano inteiro. Por outro lado, Nuñez \& Vianna (1997) relataram que esta espécie em Salta, Argentina apresentava um pico de prenhez associado à época do ano com temperatura mais alta e maior precipitação pluviométrica, em conseqüência de sua sensibilidade à desidratação, durante o estado de prenhez e de lactação.

Desmodus rotundus é considerada uma espécie poliéstrica, sem um período definido de reprodução (TADDEI et al. 1991, Alencar et al. 1994); contudo, o nascimento da maioria dos filhotes parece estar concentrado na estação mais quente e chuvosa. No presente estudo, a presença de poucos filhotes e muitas fêmeas, aparentemente não grávidas, na estação seca reforça esta hipótese, ao menos para as populações paulistas.

\section{Dimorfismo sexual}

As médias da massa corporal das fêmeas não grávidas (aqui incluídas também as lactantes), de 39,1 g, e dos machos, de 35,3 g, do Estado de São Paulo são muito próximas das obtidas por Alencar et al. (1994) para os morcegos dos Estados da Paraíba, Pernambuco e Sergipe (médias de 38,9 g para fêmeas e 35,2 g para machos). Essas médias diferem das obtidas por Wimsatt (1969) para as populações de D. rotundus do México, que apresentaram uma massa corporal média de $31 \mathrm{~g}$ para fêmeas e 30,5 g para machos. Sabe-se que as populações mexicanas pertencem a subspécie $D$. rotundus murinus, que apresenta um porte menor quando comparado com a subspécie sulamericana D. rotundus rotundus (Koopman 1988).

No presente estudo, a média do comprimento do antebraço direito e esquerdo dos morcegos hematófagos foi praticamente a mesma tanto nas fêmeas $(64,1$ e $64,0 \mathrm{~mm}$, respectivamente), como nos machos (61,2 $\mathrm{mm}$ em ambos antebraços). Alencar et al. (1994), analisando 151 morcegos adultos do nordeste brasileiro, obtiveram resultados médios de $63,1 \mathrm{~mm}$ para fêmeas e $60,6 \mathrm{~mm}$ para machos. O fato das fêmeas serem maiores que os machos em $D$. rotundus pode ser explicado pela seleção adaptativa de machos e fêmeas. Segundo Ralls (1976), uma mãe maior tem melhores condições de produzir filhotes viáveis que as mães menores e os machos poderiam estar sujeitos à seleção que não necessite de maior tamanho alar. Por esta hipótese, chamada de "big mother" (RaLls 1976), a condição de se ter maior superfície alar nas fêmeas de $D$. rotundus sugere uma capacidade de carga superior para compensar o aumento de peso durante a gravidez e para carregar o filhote nos meses iniciais após o nascimento.

\section{AGRADECIMENTOS}

Agradecemos aos funcionários da Coordenadoria de Defesa Agropecuária do Estado de São Paulo pelo auxílio nas atividades de campo, aos Profs. Drs. Eduardo Massad e Wagner A. Pedro pelas valiosas sugestões feitos a Dissertação de Mestrado do primeiro autor e incorporadas ao presente manuscrito e aos consultores da Revista Brasileira de Zoologia (Prof. Dr. Adriano L. Peracchi e outro anônimo) pelas sugestões e críticas que melhoraram sensivelmente a apresentação deste trabalho.

\section{REFERÊNCIAS BIBLIOGRÁFICAS}

Acha, P.N \& M. Málaga-Alba. 1988. Economic losses due to Desmodus rotundus, p. 208-213. In: A.M. Greenhall \& U. SChMidT (Eds). Natural history of vampire bats. Boca Raton, CRC Press, 246p.

Alencar, A.O; G.A.P. Silva; M.M. Da Arruda; A.J. Soares \& D.Q. Guerra. 1994. Aspectos biológicos e ecológicos de Desmodus rotundus (Chiroptera) no nordeste do Brasil. PesquisaVeterinária Brasileira, Rio de Janeiro, 14(4): 95-103.

Anthony, E.L.P. 1988. Age determination in bats, p. 47-57. In: T.H. KunZ (Ed.). Ecological and behavioral methods for the study of bats. Washington, DC, Smithsonian Institution Press, 533p.

Revista Brasileira de Zoologia 21 (3): 629-638, setembro 2004 
Bredt, A.; F.A.A. Araujo; J. Caetano-Jr; M.G.R. Rodrigues; M.Yoshikawa \& M.M.S. SiLva. 1998. Morcegos em áreas urbanas e rurais: Manual de manejo e controle. Brasília, Fundação Nacional de Saúde, 117p.

Bredt, A.; W. Uieda \& E.D. Magalhães. 1999. Morcegos cavernícolas da região do Distrito Federal, Centro Oeste do Brasil (Mammalia, Chiroptera). Revista Brasileira de Zoologia, Curitiba, 16 (3): 731-770.

Crespo, J.A; J.M. Vanella; B.D. Blood \& J.M. de Carlo. 1961. Observaciones ecológicas del vampiro Desmodus rotundus en el norte de Córdoba. Revista del Museu Argentino de Ciências Naturais Bernadino Rivadavia, Buenos Aires, 4 (6): 131-160.

Dean, A.G.; J.A. Dean; D. Coulombier; K.A. Brendel; D.C. Smith; A.H. BurTon. 1994. Epi info, version 6: a word processing database and statistics program for epidemiology on microcomputers. Atlanta, Centers of Disease Control and Prevention, 589p.

De Verteuil, E.M.D. \& F.W. Urich. 1935. The study and control of paralytic rabies transmitted by bats in Trinidad, British West Indians. Transactions of the Royal Society of Tropical Medicine and Hygiene, London, 29 (4): 320-358.

Ditmars, R.L. \& A.M. Greenhall. 1935. The vampire bats: presentation of underscribed habits and review of its history. Zoologica, New York, 19 (2): 53-76.

GREENHALL, A.M. 1963. Use of mist nets and stricnine for vampire control in Trinidad. Journal of Mammalogy, Lawrence, 44 (3): 396-399.

- 1993. Ecology and bionomics of vampire bats in Latin America, p. 3-57, In: A.M.Greenhall; M. Artois \& M. FekAdu (Eds). Bats and rabies. Lyon, Ed. Fond. Marcel Mérieux, 107p.

Greenhall, A.M; G. Joermann \& U. Schmidt. 1983. Desmodus rotundus. Mammalian Species, Washington, DC, 202: 1-6.

KoOpman, K.F. 1988. Systematics and distribution, p. 7-17. In: A.M. Greenhall \& U. Schmidt (Eds). Natural history of vampire bats. Boca Raton, CRC Press, 246p.

$\mathrm{MAC}_{\mathrm{AB}}$, B.K. 1973. Energetics and the distribution of vampire bats. Journal of Mammalogy, Lawrence, 31: 227-268.

NowAK, R.M.1991. Walker's mammals of the World. Baltimore, The Johns Hopkins University Press, $5^{\text {th }}$ ed., 1692p.

NuñEz, H.A. \& M.L. Vianna. 1997. Estacionalidad reproductiva en el vampiro común Desmodus rotundus en el Valle de Lerma (Salta, Argentina). Revista de Biologia Tropical, Salta, 45(3): 1231-1235.

Recebido em 15.VII.2003; aceito em 30.VII.2004.
. 1998. Abundancia y proporción sexual en el vampiro común Desmodus rotundus (Chiroptera, Phyllostomidae): Un problema de muestro?. Boletín de la Sociedad de Biología de Concepción Chile 69: 171-174.

RACEY, P.A. 1988. Reproductive assessment in bats, p. 31-43. In: T.H. Kunz. (Ed.). Ecological and behavioral methods for the study of bats. Washington, DC, Smithsonian Institution Press, 553p.

RaLLS, K. 1976. Mammals in which females are larger than males. The Quarterly Review of Biology, Chicago, 51: 245-269.

SAZIMA, I. 1978. Aspectos do comportamento alimentar do morcego hematófago Desmodus rotundus. Boletim de Zoologia da Universidade de São Paulo, São Paulo, 3: 97-119.

Schneider, M.C.; C. Santos-Borgoa; J. Aron; B. Muñoz; S. RuizVelasco \& W. Uieda. 1996. Potential force of infection of human rabies transmitted by vampire bats in the Amazonian region of Brazil. American Journal of Tropical Medicine and Hygiene, Philadelphia, 5: 680-684.

Schneider, M.C.; J. Aron; C. Santos-Burgoa; W. Uieda \& S. RuizVelasco. 2001. Common vampire bat attacks on humans in village of the Amazon region of Brazil. Cadernos de Saúde Pública, Rio de Janeiro, 17 (6): 1531-1536.

Schmidt, C. 1988. Reproduction, p. 99-109. In: A.M. GreENHALL $\&$ U. S CнміDт (Eds). Natural history of vampire bats. Boca Raton, CRC Press, 246p.

Taddei, V.A.; C.A. Gonçalves; W.A. Pedro; W.J. Tadei; I. Kotait \& C. ARIETA. 1991. Distribuição do morcego vampiro Desmodus rotundus no Estado de São Paulo e a raiva dos animais domésticos. Campinas, Impresso Especial da CATI, $107 \mathrm{p}$.

TURNER, D.C. 1975. The vampire bat. A field study in behavior and ecology. Baltimore, The Johns Hopkins University Press, 145p.

Uieda, W.; M.M. Hayashi; L.H. Gomes \& M.M.S. Silva. 1996. Espécies de quirópteros diagnosticadas com raiva no Brasil. Boletim do Instituto Pasteur, São Paulo, 2 (1): 17-36.

WiLKINSON, G.S. 1988. Social organization and behavior, p. 8595. In: A.M. Greenhall \& U. Schmidt (Eds). Natural History of Vampire Bats. Boca Raton, CRC Press, 246p.

. 1990. Food sharing in vampire bats. Scientific American, Washington, DC, 262 (2): 64-70.

WimsatT, W.A. 1969. Transient behavior, nocturnal activity patterns, and feeding efficiency of vampire bats (Desmodus rotundus) under natural conditions. Journal of Mammalogy, Lawrence, 50: 233-44. 